\title{
Interrelated of food safety, food security and sustainable food production
}

\author{
Anis Munirah M.S. and *Norfarizan-Hanoon N.A. \\ Nutrition and Dietetic Programme, School of Health Sciences, Universiti Sains Malaysia, 16150 Kubang \\ Kerian, Kelantan.
}

\begin{abstract}
Article history:
Received: 29 December 2020

Received in revised form: 3

February 2021

Accepted: 29 May 2021

Available Online: 31 January 2022

Keywords:

Food safety,

Food security,

Sustainable food production, Nutrition,

Agriculture
\end{abstract}

DOI:

https://doi.org/10.26656/fr.2017.6(1).696

\begin{abstract}
Food security and food safety are key aspects of healthy and sustainable food production. However, threats of natural disasters and diseases are grave concerns that serious precautions need to be taken as the threats may be harmful to the agricultural industry. Currently, food insecurity has become a significant big challenge in food chain supply, and there is an urgency for the government to address the issue. The aim of this review paper was to understand the relationship of food safety, food security and sustainable food production to ensure a sustainable food system to maintain adequate nourishment for the growing world population. The collaboration between governments, academicians, producers, and consumers is fundamental to raising awareness about the importance of food security. Nutrition educators can help at the grassroots level to identify the problems and help to find possible solutions. Modern technology such as RFID tags and blockchain could offer possible solutions to improve food security and sustainability. This will ensure that food products become safer and consumers can have access to precise information before consuming the products. Multidisciplinary teams must create many initiatives to ensure sustainable food systems, food safety, and food security. Reprocessing food will be the best way to eliminate food loss and food waste to sustain the food supply chain.
\end{abstract}

\section{Introduction}

Global food demands have been rapidly increasing, and the trend may continue for a decade as the life span is also rising. In Europe and North America, food supply is mainly sourced from livestock products; meanwhile, many other regions in the world predominantly source their food supply from cereal grains (Carvalho, 2006). Eighty per cent of the poor population in developing countries live in rural areas and primarily depend on agriculture (Carvalho, 2006). However, agricultural production is very imperative as it is necessary to decrease poverty and, at the same time, sustain food safety and achieve food security (Lipper et al., 2014). Furthermore, in South Asia and sub-Saharan Africa, agriculture is their key economic and employment source, but currently, more than $20 \%$ of their population is on average food insecurity (Lipper et al., 2014). Globally, many challenges needed to be addressed to provide a healthy life while conserving natural resources.

In an effort to address the challenges, products that are marketed as organic and locally grown become increasingly known by many (Feldmann and Hamm,
2015). However, numerous natural disasters such as pollution, soil erosion, and loss of biodiverse landscapes have resulted in a higher need for food, which becomes a dynamic challenge in food safety and sustainable food production (Tilman et al., 2011).

In recent times, food production is facing food safety and food insecurity crisis caused by numerous natural disasters and diseases. It is also due to activities committed by irresponsible humans driven by globalization and urbanization activities leading to a natural disaster. For example, floods are often the result of soil erosion because of deforestation, causing chemicals, heavy metals, and other pollutants to pollute the water and agricultural land.

However, an outbreak of diseases can make animalsourced food products highly contagious. High morbidity and mortality have a significant impact on the economy of the producers and, at the same time, reduce safe food products (Tilman et al., 2011), causing a public health risk.

In order to ensure food security and sustainable food production, society must strike a balance between 
ensuring adequate nourishment for growing world population while maintaining or improving the food system. Many holistic approaches need to be taken by multidisciplinary teams involving experts from academia, industry, and government. These teams must collaborate hand in hand to solve the problems and engage the public to educate them about understanding the importance of food safety and food security as well as sustainable food production. Therefore, this review aimed to understand the relation of food safety, food security and sustainable food production as they are interconnected with each other that can help to improve the food production for a better one.

\section{Food safety and food security}

Food safety can be defined as a scientific discipline in describing three major aspects: handling, preparation, and storage of food to prevent contamination and foodborne illnesses (WHO, 2019). It is also a way to preserve the quality of food. Foodborne illness can occur at any time because of our inability to detect dangers in the food that we consumed. Unsafe food means that the food has been exposed to dirt, germs and most of them are infections caused by bacteria, viruses, and parasites that we are unable to detect with our naked eyes. Other than that, harmful toxins and chemicals are also the main reason for foodborne illnesses when the foods are contaminated (CDC, 2020).

On the other hand, food security allows people to have sufficient access to nutritious food to meet their daily dietary demands and needs to stay healthy (IFPRI, 2020). Nevertheless, there are a few factors that contribute to food insecurity. Over a decade, climate change, increasing world population, the increase in the price of food supply, and other environmental factors have created an impact on food security. Several strategies need to be executed to adapt to the current situation and increase the sustainability of food production, especially crop production. Reprocessing foods is the best option to eliminate or reduce food loss or food waste. For example, sustainable intensification and source reduction can intensify the harvest of vegetable crops to double the output despite having the same footprints.

\section{Relationship between food safety and food security}

Most people are aware that food safety and food security are the key aspects of the food system to establish a healthy population. Food safety and food security are everyone's business. However, in the twenty -first century, increasing challenges have to be faced to ensure that the foods consumed are safe and nutritious.
Food safety and food security are the two complementing elements that sustain the food system. By the year 2050, food production needs to be increased by more than $50 \%$ of the 2012 production level to meet global demands (Garcia et al., 2020). Demands for food production is increasing rapidly as the environmental and natural resources impact sustainable food production.

Food security is prioritizing concerns over ongoing food shortage and hunger in resource constraints set. Food insecurity affects those with low salaries most, raising starvation and malnutrition (Arezki and Bruckner, 2011). Regarding food safety and food security issues, malnutrition becomes a challenge as it increases populations. Food security always prioritizes food safety over healthy nutrition. To have a healthy, sustainable food production and food system, food safety and food security must come into action together. An impactful solution for our future food system is needed to achieve the United Nations Sustainable Development Goals (SDG) to eradicate hunger and poverty, provide clean water and sanitation, responsible production and consumption, action for climate change, and sustain life on land and water (Vågsholm et al., 2020).

\section{Food safety and food security needs from the new perspectives}

The strategies used to achieve food security must be synchronized with food safety and research and development to construct a sustainable food system. For example, many studies on Norovirus (NoV) have been conducted, involving humans, animals, plants, and other environmental factors that are elemental in the transmission of disease. Human norovirus $(\mathrm{HuNoV})$ has been documented as one of the factors that can cause foodborne diseases. The virus can be widely spread from one person to another through physical contact, faecal materials, and contaminated food are consumed (Painter et al., 2013).

In the agriculture sector, outbreaks can occur through improper handling, poor hygiene, and contaminated surface. There is evidence that the DNA norovirus can switch from a plant host to a vertebrate host (Roperch et al., 1999) (Figure 1). The DNA of the plant virus is transmitted to humans or animals by undergoing recombination with the RNA. Twenty years have passed since the analysis was conducted. Thus, a new analysis is needed to obtain more information about the genomics and availability of DNA and protein sequencing data. Further research is required in this field. The use of technology is very helpful to broaden the knowledge of microbial that can cause foodborne illnesses. The use of the quantitative polymerase chain reaction (PCR) and next-generation sequencing (NGS) 
has been proven to elucidate the interaction of those pathogens (Ronholm et al., 2016).

Nevertheless, by using technology or the Internet, the global food system will be further improved and become considerably productive (Johnson et al., 2018). The technology offers more sources to make a reduction, reprocessing, and recycling of food.

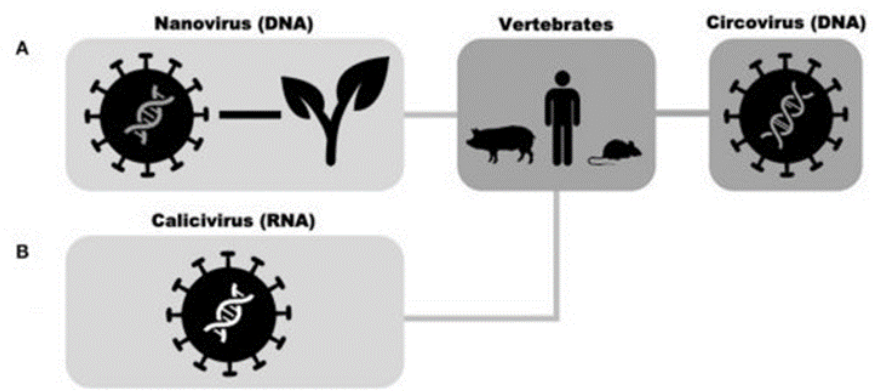

Figure 1. Example of how norovirus transmits from plant to human.

Source: Garcia et al. (2020)

\section{The threat of environmental disasters and disease}

The perception of the public towards foodborne illness is increasing daily (Callawaya and Sheridanb, 2015). According to the World Health Organization (WHO), an estimated 600 million people worldwide are falling ill after consuming contaminated food (Mehlhorn, 2015). Eight hundred twenty million people had suffered from food insecurity and experienced hunger and suffered from malnourishment, especially being undernourished (Garcia et al., 2020). They live in poverty and cannot achieve sustainable food production. Their situation is worsened by natural disasters such as hurricanes, floods, and tornadoes, which have become factors that have significant impacts on food insecurity and food unsafety, as addressed by the Food and Agriculture Organization (FAO)(Garcia et al., 2020). Thus, poverty causes people to become extremely vulnerable to these disasters and disrupt food production and access to the food supply.

Disasters also impact communities through death, injury, trauma, and damage to communities and infrastructure (Lindell and Prater, 2004). It also can risk human health, animal health, and environmental health. For example, diarrheal disease often occurs after a flood due to consuming contaminated food or water contaminated with many pollutants such as E.coli, Salmonella, and Shigella (OSHA, 2003). Most vulnerable groups have limited access to medical treatment, which further affects human health. At the same time, agriculture is also affected as many plants and animals will be submerged by the rising floodwater.

Developing countries are most vulnerable to economic and health impacts after a disaster occurs. A study conducted by FAO showed that natural disasters in 2003-2013 had a 25\% impact on the agriculture sectors (Garcia et al., 2020). The population recovering from a disaster is exceedingly vulnerable to food security and food safety (Tilman et al., 2011).

Transboundary diseases had posed threats to the health of humans, animals, and the well-being of ecosystems worldwide. For example, in recent times, African Swine Flu (ASF) had affected swine and wild boars, resulting in $100 \%$ fatality rates (Gallardo and Arias, 2019). It affected many countries such as Europe, Russia, and China. This outbreak had slightly affected China's economy as they are the largest producers of food products (Hayes et al., 2019). On the other hand, the strain of avian influenza such as $\mathrm{H} 5 \mathrm{~N} 1 \mathrm{had}$ also instigated a pandemic leading to the development of human to human transmission. Such cases had caused global health concerns and, in some cases causing the entire chicken population to be destroyed, causing epizootic and preventing severe acute respiratory syndrome (SARS) from spreading. It did not only affect health issues; rural farmers who sold the chicken also suffered significant losses as all the infected chicken must be destroyed or burnt (Lockerbie and Herring, 2005).

Other than that, unintentional chemical contamination in food production can be hazardous to humans and animals. Chemical contaminants include agrochemicals, environmental/industrial contaminants, and many more. It can cause contaminants at any point in the food supply and may accumulate in animals and humans. Thus, it may lead to many acute health impacts when the concentration in an organism's tissues increases. Day by day, it will create a colossal impact on health as repetitive exposure occurred.

As we all know, food is a vehicle for transporting bacteria. Antimicrobial resistance (AMR) microorganisms can cause a silent pandemic at present (Jasovsky et al., 2016), affecting most food producers around the globe. Detection of antimicrobial substances in food products is still not common, but the findings of bacteria with genes for antimicrobial resistance is frequent. For example, 1395 samples were taken in 2016 from animal products, including meat, dairy products, egg, fish, and honey. However, only 1 sample is positive for antimicrobial resistance (Nordlander et al., 2018). The Biological Hazard panels of the European Food Safety Authority (EFSA) published a journal representing AMR's opinions regarding foodborne hazards. The first are concerns about food safety risks. The second view is the use of carbapenems to treat 
serious infections in humans and the presence of resistance in animals (Panel and Biohaz, 2013). Both opinions showed that foodborne pathogens displayed diverse ranges of resistance to antimicrobial agents of humans. The spreading of bacteria resistance in food influences the health of the community.

Disasters and diseases have resulted in an agriculture crisis and interrupt humans, animals, environmental health, and well-being, which may worsen food safety and compromise food security in the longer term. The crisis of the Food and Agriculture sector may have a massive impact on the global economy. Therefore, multidisciplinary collaboration must be taken seriously to prevent, respond to, and recover from the crisis.

\section{Sustainable food security: a political imperative and challenge}

Sustainability of food security includes availability and sufficiency of food production, accessibility, and the ability to purchase food and sufficient nutrition as well as safety to consume the food (Swaminathan, 2015). Social unrest and global wars could result in prolonged food insecurity and famines. Food insecurity is a crucial threat to all (public health, social, and political). This challenge is expected to rapidly increase to nearly 10 billion in 2050 (United Nations, 2019). Sustainably feeding 10 billion people requires changes in the food supply in the next future. The reduction of food losses and food wastes that are needed may probably be a part of the solution.

Reducing and eliminating global food loss and food waste will probably feed billions of people around the globe. Reducing tons of food waste will lead to more sustainable land use and water resources can be managed better. Climate changes will improve and sustain lives, land, and water as well. A responsible political group must advocate a novel action in handling this issue. For example, the European Parliament came out with a solution of eliminating food waste in the EU by $30 \%$ and $50 \%$ in 2025 and 2030, respectively (European Parliament, 2017). The approach that they practice is to make food donations easier, and the "best before" and "use by" labels are less confusing to the community.

\section{Initiatives for sustainable food system, food safety and food security}

To counter back the threat of transboundary disease and natural disasters, incentive measures need to be executed to help people make full use of their land and food production system so the expanding population can be fed.
As shown in Figure 2, multidisciplinary teams must collaborate in making sure that this crucial problem can be solved. This collaboration can facilitate the increase of human health, the environment, and the use of allnatural resources. One Health is a concept that interrelates the health of people, animals, and the environment where multidisciplinary teams work together to resolve any related problems. It can be applied to transform and increase sustainable practices in the agricultural sector and simultaneously maintain and improve the health and well-being of all humans, animals, and the environment. It is an initiative by policymakers such as World Health Organization (WHO), United Nations Food and Agriculture Organization (FAO), United States Center for Disease Control (CDC), and the European Union (EU) with One Health European Joint Programme (OHEJP) (FAO, 2020). Their strategy is to prevent and control diseases that have the potential to become a public health risk. Most of the approaches focus on zoonotic disease which can be transmitted from animals to the human population and vice versa (Garcia et al., 2020). One Health Curricular framework is created for the purpose of food safety and food security (Angelos et al., 2016). These aims need to be accomplished as the One Health Curricular framework is designed to assist in the curriculum to train the generation and food system workers. It is immeasurably needed to develop knowledge and skills for an interdisciplinary team to solve problems concerning food safety and security. Raising the awareness of the public is the responsibility of the One Health Practitioners (Togami et al., 2018). Hence, it is fundamental to implement and practise the concept of One Health food safety and security as $63 \%$ of farmers are over 55 years old and $2 \%$ of the population are employed in the agriculture sector in the United States (Ahearn and Newton, 2009). The agriculture sector is having trouble as they have a

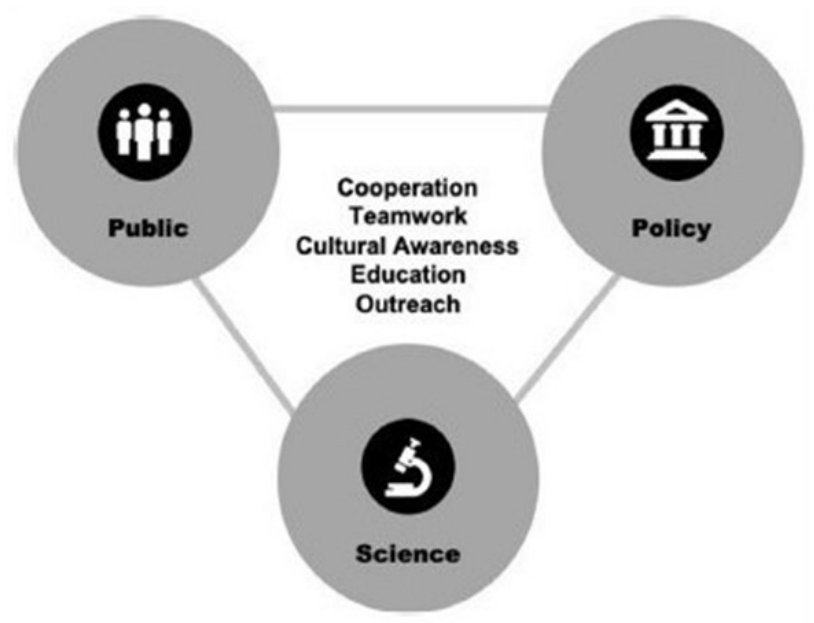

Figure 2. One Health approach to creating awareness to the public

Source: Garcia et al. (2020) 
shortage of farmers and this may cause a negative impact on food production. The One Health concept may lead to more future generations engaging in the agricultural sector in terms of employment and education.

The upsurge in the growth of the global population has increased the number of better-nourished people moving from the consumption of basic staple food to more processed and ready to eat food. Thus, it may lead to an increasing number of foodborne outbreaks and diseases. Therefore, initiatives must be made to improve the health of the human population.

The government must also collaborate with food system researchers and advocates in the development of food security and food safety measures and at the same time support the growth of sustainable food production and amplify the efforts to reach the goal of healthy nutrition. Multidisciplinary research is much needed to enhance the understanding of the mechanism of the organism and the environment to provide sustainable food production for future generation.

An increase in global food trade has also led to the issue of affected products, internationally and domestically, causing increased incidences of foodborne illness as well as animal and plant diseases (King et al., 2017). There is an urgency to stop the outbreaks in their tracks by implementing a new legal requirement for traceability and exporting countries to comply with all the regulations imposed by the importing countries (Charlebois et al., 2014). For example, current new advancements in technology in RFID and the incorporation of data logger capabilities and integrated sensors have introduced the RFID technology in the food traceability system (Costa et al., 2013). Apart from that, integrated high-throughput DNA sequencing and metabolomics approach can trace the presence of the pathogen, specific toxin, metabolites, antibiotics, and pesticides in foodstuff (Ferri et al., 2015). The RFID tags help track food products by providing real-time information on the food product's identity and the food chain. It also provides data for analyzing the causes of food loss and food waste. However, using a blockchain can be more efficient and reduce paperwork (Ahmed and Broek, 2017). Blockchain helps to increase more sustainable food products and food security. The traceback of outbreaks will be faster and more precise when using blockchains as it will speed up the procedures.

Nevertheless, to increase food safety and help to sustain food production, it is crucial to take full advantage of the use of social media. The Internet can be an effective communicator as information can be delivered quickly (Chapman et al., 2014). However, misinformation about society can also occur as there is an increasing number of "influencers" on the Internet who do not have a background in food safety or food science. This is the biggest challenge for educators to convey knowledge to society about the importance of food safety and food security to sustain food production. However, the benefits outbid the challenges as social media mediums are the fastest, accessible at all times, and a very interactive way of raising awareness about the issue. Overall, food safety professionals need to be proactive in creating accurate information to educate the consumers.

Besides, nutritionists or nutrition educators can also help to contribute in many ways. For example, they can help at the grassroots level to identify the problems and find the solution. In this field, nutrition educators are needed to listen to people's problems and experiences in designing the solution to cater to the problem. Moreover, they can also contribute to research and development, analysis, and health intervention (Hamm and Bellows, 2003). Nutrition educators can contribute by transferring technical training to the community about the issues raised. Feeding 10 billion people in 2050 sustainably requires significant changes in our food chains. Changing food demands from animal-based to plantbased diet can benefit the world's cereal production (Willett et al., 2019). The future diets must be synchronized with recommendations from the EATLancet Plate report (Kearny, 2019) or recommended food intake according to the My Healthy Plate, albeit with local adaptations.

Without food safety, we cannot achieve food security and sustainable food production. Many challenges need to be resolved by the food system researchers to establish ways to improve the compatibility of healthy nutrition with food security, in many aspects such as political perspective, increase the traceability of food products, and many more. An adequate supply of healthy and safe foods that can be consumed by people all around the world can result in free poverty and hunger.

\section{Conclusion}

Food security is seen as a social development that could lead to the world being able to feed over 10 billion people worldwide adequately. On a global scale, inadequate technology, techniques of food production pose significant risks to food safety and food security. Innovative agriculture practices and technologies are needed. Technological development needs to prevail over critical challenges posed by global food demands in the next future. It is imperative to develop new adaptation strategies to address climate change for better 
food safety and food security.

Development and initiatives covered in this paper, including creating awareness to the consumers, will benefit global food security as a sufficient amount of affordable, safe food can be offered. Also, to sustain and produce enough secure and safe food, efficient and effective food chains are required. Educating and creating awareness among consumers via social media needs to be prioritized to utilize a flexible and responsive approach to food challenges.

\section{Conflict of interest}

The authors declare no conflict of interest.

\section{References}

Ahearn, M. and Newton, D. (2009). Beginning Farmers, and Ranchers., Economic Information Bulletin Number 53. Retrieved on August 15, 2020 from ERS, USDA. Website: https://www.ers.usda.gov/ webdocs/publications/44395/9417_eib53_1_.pdf? $\mathrm{v}=3324.7$

Ahmed, S. and Broek, N. (2017). Blockchain could boost food security. Nature, 550, 43. https:// doi.org/10.1038/550043e

Angelos, J., Arens, A., Johnson, H., Cadriel, J. and Osburn, B. (2016). One Health in food safety and security education: A curricular framework. Comparative Immunology, Microbiology, and Infectious Diseases, 44, 29-33. https:// doi.org/10.1016/j.cimid.2015.11.005

Arezki, R. and Bruckner, M. (2011). Food Prices and Political Instability. IMF Working Papers, 11(62), 122. https://doi.org/10.5089/9781455221066.001

Callawaya, T.R. and Sheridanb, T.G. (2015). Smarter arrow is now available in the food safety quiver. Proceedings of the National Academy of Sciences of the United States of America, 112(40), 1223012231. https://doi.org/10.1073/pnas.1516670112

Carvalho, F.P. (2006). Agriculture, pesticides, food security, and food safety. Environmental Science and Policy, 9(7-8), 685-692. https://doi.org/10.1016/ j.envsci.2006.08.002

CDC (Centers for Disease Control and Prevention) (2020). Foodborne Germs and Illnesses. Retrieved on August 5 ,2020 from CDC website: https:// www.cdc.gov/foodsafety/foodborne-germs.html.

Charlebois, S., Sterling, B., Haratifar, S. and Naing, S.K. (2014). Comparison of Global Food Traceability Regulations and Requirements. Comprehensive Reviews in Food Science and Food Safety, 13(5), 1104-1123. https://doi.org/10.1111/1541-
4337.12101

Feldmann, C. and Hamm, U. (2015). Consumers' perceptions and preferences for local food: A review. Food Quality and Preference, 40(Part A), 152-164. https://doi.org/10.1016/j.foodqual.2014.09.014

Food and Agriculture Organization (FAO) (2020). ONE HEALTH: of the United Nations Strategic Action Plan. Retrieved on August 2, 2020 from FAO website: http://www.fao.org/one-health/en/

Gallardo, C. and Arias, M. (2019). African swine fever (ASF) diagnosis, an essential tool in the epidemiological investigation. Virus Research, 271, 197676.

https://doi.org/10.1016/ j.virusres.2019.197676

Garcia, S.N., Osburn, B.I. and Jay-Russell, M.T. (2020). One Health for Food Safety, Food Security, and Sustainable Food Production. Frontiers in Sustainable Food Systems, 4(January), 1-9. https:// doi.org/10.3389/fsufs.2020.00001

Hamm, M.W. and Bellows, A.C. (2003). Community food security and nutrition educators. Journal of Nutrition Education and Behavior, 35(1), 37-43. https://doi.org/10.1016/S1499-4046(06)60325-4

Hayes, D.J., Li, M., Xiong, T., Ji, Y., Hayes, D. and Zhang, W. (2019). African Swine Fever in China: An Update. Center for Agricultural and Rural Development (CARD), Agricultural Policy Review. Iowa State University. Retrieved from CARD website: https://www.card.iastate.edu/ ag_policy_review/article/?a=91

IFPRI (International Food Policy Research Institute) (2020). Food security. Retrieved on 12 August, 2020 from IFPRI website: https://www.ifpri.org/topic/food -security.

Jasovsky, D., Littmann, J., Zorzet, A. and Cars, O. (2016). Antimicrobial resistance - a threat to the world's sustainable development. Upsala Journal of Medical Sciences, 121(3), 159-164. https:// doi.org/10.1080/03009734.2016.1195900

Johnson, L.K., Dunning, R.D., Bloom, J.D., Gunter, C.C., Boyette, M.D. and Creamer, N.G. (2018). Estimating on-farm food loss at the field level: A methodology and applied case study on a North Carolina farm. Resources, Conservation, and Recycling, 137, 243-250. https://doi.org/10.1016/ j.resconrec.2018.05.017

Kearny, A.T. (2019). How Will Cultured Meat and Meat Alternatives Disrupt the Agricultural and Food Industry? Retrieved on October 8, 2020 from ATKearny website: http://media.enfasis.com/ adjuntos/146/documentos/000/132/0000132740.pdf.

King, T., Cole, M., Farber, J.M., Eisenbrand, G., 
Zabaras, D., Fox, E.M. and Hill, J.P. (2017). Food safety for food security: Relationship between global megatrends and developments in food safety. Trends in Food Science and Technology, 68, 160-175. https://doi.org/10.1016/j.tifs.2017.08.014

Lindell, M.K. and Prater, C.S. (2004). Assessing Community Impacts of Natural Disasters. Natural Hazards Review, 4(4), 176. https://doi.org/10.1061/ (ASCE)1527-6988(2003)4:4(176)

Lipper, L., Thornton, P., Campbell, B.M., Baedeker, T., Braimoh, A., Bwalya, M., Caron, P., Cattaneo, A., Garrity, D., Henry, K., Hottle, R., Jackson, L., Jarvis, A., Kossam, F., Mann, W., McCarthy, N., Meybeck, A., Neufeldt, H., Remington, T., Sen, P.T., Sessa, R., Shula, R., Tibu, A. and Torquebiau, E.F. (2014). Climate-smart agriculture for food security. Nature Climate Change, 4(12), 1068-1072. https:// doi.org/10.1038/nclimate2437

Lockerbie, S. and Herring, D.A. (2005). Global Panic, Local Repercussions: Economic and Nutritional Effects of Bird Flu in Vietnam. In Hahn, R.A. and Inborn, M. (Eds). Anthropology and Public Health: Bridging Differences in Culture and Society. United Kingdom: Oxford Scholarship Online.

OSHA (Occupational Safety and Health Administration) (2003). Protect Yourself. Flood Cleanup. Retrieved on August 24, 2020 from OSHA website: https:// www.osha.gov/OshDoc/data_Hurricane_Facts/ Bulletin2.pdf.

Painter, J.A., Hoekstra, R.M., Ayers, T., Tauxe, R.V., Braden, C.R., Angulo, F.J. and Griffin, P.M. (2013). Attribution of foodborne illnesses, hospitalizations, and deaths to food commodities by using outbreak data, United States, 1998-2008. Emerging Infectious Diseases, 19(3), 407-415. https://doi.org/10.3201/ eid1903.111866

Panel, E. and Biohaz, H. (2013). Scientific Opinion on Carbapenem resistance in food animal ecosystems. EFSA Journal, 11(12), 1-70. https://doi.org/10.2903/ j.efsa.2013.3501

Ronholm, J., Nasheri, N., Petronella, N. and Pagotto, F. (2016). Navigating microbiological food safety in the era of whole-genome sequencing. Clinical Microbiology Reviews, 29(4), 837-857. https:// doi.org/10.1128/CMR.00056-16

Roperch, J.P., Lethrone, F., Prieur, S., Piouffre, L., Israeli, D., Tuynder, M., Nemani, M., Pasturaud, P., Gendron, M.C., Dausset, J., Oren, M., Amson, R.B. and Telerman, A. (1999). SIAH-1 promotes apoptosis and tumor suppression through a network involving the regulation of protein folding, unfolding, and trafficking: Identification of common effectors with p53 and p21(Waf1). Proceedings of the National Academy of Sciences of the United States of America, 96(14), 8070-8073. https:// doi.org/10.1073/pnas.96.14.8070

Swaminathan, M.S. (2015). Food Security and Social Protection. In Swaminathan, M.S. (Ed). Combating Hunger and Achieving Food Security. United Kingdom: Cambridge University Press. https:// doi.org/10.1017/CBO9781316389485.019

Tilman, D., Balzer, C., Hill, J. and Befort, B.L. (2011). Global food demand and the sustainable intensification of agriculture. Proceedings of the National Academy of Sciences of the United States of America, 108(50), 20260-20264. https:// doi.org/10.1073/pnas. 1116437108

Togami, E., Gardy, J.L., Hansen, G.R, Poste, G.H., Rizzo, D.M., Wilson, M.E. and Mazet, J.A.K. (2018). Core Competencies in One Health Education: What Are We Missing? Discussion paper. National Academy of Medicine. Washington DC. https://doi.org/10.31478/201806a

United Nations. (2019). How certain are the United Nations global population projections? Department of Economic and Social Affairs. Population Prospects 2019. Retrieved on September 22, 2020 from UN website: https://www.un.org/en/ development/desa/population/publications/pdf/ popfacts/PopFacts_2019-6.pdf

Vågsholm, I., Arzoomand, N.S. and Boqvist, S. (2020). Food Security, Safety, and Sustainability- Getting the Trade-Offs Right. Frontiers in Sustainable Food Systems, 4, 1-14. https://doi.org/10.3389/ fsufs. 2020.00016

Willett, W., Rockström, J., Loken, B., Springmann, M., Lang, T., Vermeulen, S., Garnett, T., Tilman, D., DeClerck, F., Wood, A., Jonell, M., Clark, M., Gordon, L.J., Fanzo, J., Hawkes, C., Zurayk, R., Rivera, J.A., De Vries, W., Majele Sibanda, L., Afshin, A., Chaudhary, A., Herrero, M., Agustina, R., Branca, F., Lartey, A., Fan, S., Crona, B., Fox, E., Bignet, V., Troell, M., Lindahl, T., Singh, S., Cornell, S.E., Srinath Reddy, K., Narain, S., Nishtar, S. and Murray, C.J.L. (2019). Food in the Anthropocene: the EAT-Lancet Commission on healthy diets from sustainable food systems The Lancet Commissions, 393(10170), 447-492. https:// doi.org/10.1016/S0140-6736(18)31788-4

World Health Organization (WHO), (2019). Food Safety WHO. Retrieved on September 13, 2020 from WHO website: https://www.who.int/news-room/factsheets/detail/food-safety 